\title{
O signo para Humboldt, para Saussure e para Bakhtin
}

\author{
The sing for Humboldt, for Saussure and for Bakhtin
}

\section{Sebastião Elias Milani}

Universidade Federal de Goiás-UFG - Goiânia - Goiás - Brasil

\begin{abstract}
Resumo:Este artigo mostra três das principais concepções de signo dos estudos sobre a linguagem, diferenças e semelhanças. Para Humboldt, o signo é a representação material ou a imagem acústica para o conceito, a ele se soma a identidade do som articulado da língua. Essas três partes, signo, conceito e identidade do som, constroem as formas da língua que são as palavras. Para Saussure, signo é o nome da relação entre significante e significado. Saussure propôs a substituição dos termos imagem acústica e conceito, que estavam plenos de sugestionalidades e conceituações prévias, pelos termos significante e significado. Para Bakhtin, o signo é a forma da estrutura que realiza em som articulado um sentido, ideologicamente completado pelo pensamento. $\mathrm{O}$ encontro entre o som articulado e o conceito dá o elemento resultante da semiose, por isso todo signo é semiótico.
\end{abstract}

Palavras-chave:Signo. Humboldt. Saussure. Bakhtin.

\begin{abstract}
This article shows three of the principal sign conceptions of the studies about language, differences and similarities. The sign is for Humboldt the material representation, or sound-image, of the concept, besides the identity of the articulated language sound; these three parts, sign, concept and sound identity, make the form of the language that is the word. The sign is for Saussure the name of the relation between the signified and the signifier. Saussure proposed the substitution of the terms sound-image and concept, that were full of suggestions and prior conceptualization, to the terms signified and signifier. The sign in Bakhtin is the form of the structure that accomplishes an ideologically sense completed by thought through articulated sound. The meeting between the articulated sound and the concept gives the resulting element of semiosis, so every sign is semiotic.
\end{abstract}

Keywords: Sign. Humboldt. Saussure. Bakhtin. 


\section{Introdução}

O ponto de partida neste artigo é o de que Humboldt explicou o signo pela perspectiva do som articulado, o de que Saussure o fez pela perspectiva do sistema da língua e o de que Bakhtin o fez pela perspectiva da estrutura da linguagem. Os três entenderam a comunicação humana como uma estrutura que dá suporte ao pensamento. Nos três a preocupação com a demonstração do método é tão grande quanto com a exposição dos conceitos. Assim, os três pontos de vista são completos e exatos na análise que fazem do objeto que adotaram para estudo.

Desde a antiguidade clássica, especificamente Platão como o mais antigo, discutia-se a relação na linguagem entre o pensamento e sua manifestação. Sempre se falou que a manifestação acontecia por meio da articulação de sons e que o pensamento provia a significação e, em Platão, no Crátilo, já está explicada essa relação. Portanto, os conceitos aqui abordados são continuidade, e o que se pode mostrar de mudança entre esses pensadores é o método com o qual cada um abordou o tema, gerando a cada vez uma ruptura.

Em se tratando de terminologia metalinguística, o termo signo aparece com mais de uma significação específica. Mas, ao longo da história, em se tratando da relação entre os elementos envolvidos na realização da articulação, nomeou-se essa relação também como palavra e como nome. Citando-se alguns autores, como amostragem, em Platão e também em Aristóteles, foi chamada de nome e de palavra. Na Gramática de Port-Royal, de Arnauld e Lancelot, de signo e de palavra. Em John Locke e em Etiéne B. de Condillac, de palavra. De forma geral, o termo palavra continuou desde a antiguidade até a pós-modernidade usado para representar metalinguisticamente a relação entre a imagem acústica e o conceito.

Quando a Linguística foi feita ciência, durante o século XIX, o termo signo assumiria relevância para a metalinguagem nesse contexto. Podem ser citados Friedrich Schleicher, William D. Whitney, Karl
Brugmann etc., entre esses, Ferdinand de Saussure que, ao explicar a terminologia da Linguística, explicou também como se deveria empregar o termo signo e suas partes, o significante e o significado. Assim, após o Curso de Linguística Geral, o conceito primeiro para o termo signo é significante mais significado, unidade arbitrária que pertence ao universo concreto da língua.

Durante o século $X X$, além de Bakhtin, apresentado adiante neste artigo, outros pensadores estudaram a estrutura da língua, já como parole, a partir da relação entre significante e significado. Provavelmente, a mais brilhante de todas e também a mais profícua foi a de Louis T. Hjelmslev: a Glossemática. Hjelmslev apresentou uma divisão do enunciado em Plano de Expressão e Plano de Conteúdo, ambos comportando uma relação entre forma e substância.

Tanto Saussure, como Whitney, Schleicher, Bakhtin, Hjelmslev e também Eugenio Coseriu, Noam Chomsky, Émile Benveniste etc., pagariam muitos tributos a Wilhelm von Humboldt. Humboldt aplicaria a noção platônica, já interpretada por Condillac, Herder e Immanuel Kant, entre outros, ao estudo da linguagem. Estabeleceu dois extremos para a linguagem: forma interna e forma externa. Na forma interna, todas as estruturas linguísticas são iguais e, na forma externa, todas as estruturas linguísticas são diferentes. Aplicou-se em estudar a diversidade das formas das línguas a partir do som articulado e concluiu que é no som articulado que as línguas e todos os seus elementos se tornam diferentes entre si.

\section{Para Humboldt: signo, conceito e identidade}

Como disse Humboldt, os sons articulados se distinguem dos outros sons animais pela intencionalidade e por sua capacidade de significar. A comparação com gritos e com a sonoridade musical mostra que os sons articulados não podem ser descritos por suas características, mas somente pela maneira como são produzidos. O som, na articulação, é somente uma forma de torná-la mais facilmente 
perceptível, sendo possível separá-la dele. Então, de acordo com Humboldt, não se fala somente porque se pensa, mas porque se possui uma capacidade de juntar o pensamento e os instrumentos da língua.

A contundência dos sons articulados, segundo Humboldt, faz com que sejam mais facilmente percebidos. Quanto mais enérgica for a intenção de produzi-los, mais nítidos eles serão, pois se formam na junção ou na oposição com outros sons, e esta cooperação é necessária para a perfeição do discurso. A diversidade dos sons, que obriga cada povo a realizar somente os sons linguísticos que interessam para sua língua, é gerada pela diversidade de órgãos da fonação que interferem na articulação, pelo lugar em que esta é produzida e pelas características do som a ser produzido. As características do som devem se fundir à articulação e somente as mudanças necessárias e próprias do som devem acontecer. Para que não ocorram degenerações, jamais uma característica de um som deve ser aplicada a outro que não a tenha por sua natureza.

O sistema fônico se forma dos modos pelos quais os sons articulados se associam na formação, por semelhança ou por oposição de séries. As séries se formam a partir da totalidade de possibilidades das relações entre os sons. Na evolução fonética das línguas, sons articulados muito próximos uns dos outros tendem a se fundir ou a se confundir. De acordo com Humboldt, quanto mais precisa for mantida a distinção dos sons da língua, mais rica em possibilidades e agradável ao ouvido estrangeiro ela será. Quanto à riqueza em sons, Humboldt fala na abundância de sons necessários para a fala e na limitação a um número de sons necessários para um equilíbrio entre eles. Esses fatores têm que brotar da língua, que é como uma imensa e rica organização em que todas as partes estão relacionadas entre si. De qualquer ângulo que ela seja estudada, ao falar, os homens somente utilizam uma pequena parte dessa organização, mas nessa pequena parte está sempre pressuposta e atuante a organização inteira.

A língua forma, pelo processo de juntar sons articulados, unidades sonoras chamadas sílabas. Na formação da língua, às sílabas, unidades sonoras, vinculam-se conceitos, convertendo-as em palavras, ou seja, torna-se palavra a unidade sonora a que se vincula um conceito. Geralmente são necessárias várias sílabas para a composição de uma base sonora para um conceito. Disse Humboldt que a palavra é composta de uma dupla unidade: a do conceito e a do som. É como palavras que as unidades sonoras se convertem em fala, já que, na carência de conceito, elas não podem ser entendidas, ou não existem. Segundo Humboldt, se a língua for um mundo à parte, descrito objetiva e subjetivamente pelo indivíduo a partir das impressões que recebe da natureza, as palavras são os objetos individuais do mundo, que se compõem aos olhos dos indivíduos como parte independente e dependente do todo: são objetos distintos e por isso devem ser preservadas em suas formas distintivas.

No livro Uber die

VerschiedenheitdesmenschlichenSprachbauesundihre nEinflussauf

die geistigeEntwicklungdesMenschengeschlechts [18311835], obra traduzida para o espanhol como Sobre ladiversidad de laestructuradellenguaje humano y su influencia sobre eldesarrollo espiritual de lahumanidad(1990), Humboldt escreveu (1990: 98) "chamamos palavra ao signo que corresponde a um conceito". A forma da palavra corresponde às unidades que encerram em si uma significação, ou um conceito. O termo signo equivale à unidade sonora que leva à correspondência de um conceito. No pensamento tem-se a ideia, que gera a necessidade da articulação dos sons. No mesmo parágrafo, "a sílaba forma uma unidade sonora; só se converte em palavra quando obtém uma significação própria", Humboldt, obviamente, está fazendo referência à condição que deve ter um som articulado, como sílaba, para ganhar status de língua. As palavras mostram dupla unidade: sonora $e$ conceitual. A língua tem sempre uma forma típica na cultura para representar cada conceito. Isso é uma constante. Logo, a expressão de um conceito por meio de sons articulados segue o processo típico do modo como um povo costuma fazer: os sons 
articulados já estão previamente definidos na língua e os conceitos seguirão o modo da cultura, juntos formarão a unidade da palavra na fala.

Humboldt propõe que se veja a língua como um segundo mundo, sob a perspectiva do indivíduo, do modo como ele recebe as sensações do mundo verdadeiro. Desse modo as palavras seriam os objetos individuais desse segundo mundo, e elas são indivíduos, cujas formas devem ser preservadas. Ou seja, para que a palavra cumpra sua função de comunicar é preciso que ela mantenha a estrutura sonora de sua forma, para também manter a do sentido. Nessa condição não há censura, na medida em que a ideia está pronta na mente, o pensamento usará os recursos da língua, por meio dos sons articulados, para dar a conhecer essa ideia. Nesse fato, não é a fala que se compõe de palavras, mas as palavras que nascem do conjunto do discurso. Claramente, o que Humboldt está propondo é que o sentido das formas depende do uso delas no discurso.

A palavra é a última instância em que atua a ação formadora da língua. Ela é o produto básico da língua. No discurso, a língua se limita a prescrever uma forma reguladora para as palavras, que, enquanto formas prontas, são um conjunto de possibilidades semânticas, organizadas em torno de um sentido. No discurso, pela relação estabelecida com outras palavras e com a ideia, elas têm definido seu papel. Importante notar que a língua, na composição do discurso, limita-se a exigir um emprego que esteja previsto no conjunto de possibilidades semânticas. Nessa escolha atua a individualidade do falante, que realiza a configuração a ser dada. Mesmo que uma palavra seja empregada isoladamente, seu entendimento está atrelado a um continuum, um contexto ou uma narrativa, e esse entendimento, para ser correto, depende dos fatores linguísticos que compõem esse continuum estarem desenvolvidos na língua.

A palavra é, pois, um objeto que substitui na mente dos indivíduos outro objeto real. O objeto linguístico representa as características do objeto real, segundo o modo pelo qual esse objeto real foi percebido pelo indivíduo. Apesar de se representarem, há uma grande lacuna que separa o mundo dos objetos linguísticos do mundo dos outros objetos reais. A palavra é composta, então, de um conceito de algo que existe no mundo e que, ao se formar no interior do indivíduo, é dado a conhecer aos outros indivíduos através da articulação sonorizada. A articulação, antes de tudo, possui uma identidade que, reconhecida como um som, pertencente à língua. A articulação pode se tornar um signo, isto é, um símbolo que leva os indivíduos a identificar o conceito, a língua, o indivíduo, a nação etc. Resumindo: a palavra é o signo associado a um conceito e à identidade sonora de uma cultura. Nos casos em que a identidade sonora, mesmo reconhecida como parte da língua, não esteja clara suficiente para virar signo, o conceito não será identificado e o som não será palavra.

Essa divisão da palavra, porém, pode se tornar mais perceptível: ao ouvir /ba/, um falante da língua reconhecerá sem dificuldades que se trata de um som de sua língua materna. Portanto, encontrou uma identidade para este som, que é, com certeza, um símbolo da língua, uma vez que ela foi reconhecida neste som. Por isso /ba/ é um signo dessa língua. No entanto, /ba/ em princípio não possui conceito e, para que se forme um conceito, vai-se precisar de mais unidades sonoras adicionais. Segundo Humboldt, a identificação como som de uma língua, ou mesmo como um som articulado, é a identidade do som, mas não é suficiente para ser signo de um conceito. É interessante observar que, em geral, para ter uma palavra, os seres humanos fazem uso de vários sons, que são certamente frutos de uma elaboração e de um amadurecimento linguísticos que se deram ao longo de gerações. Então, /ba/ não é uma palavra, porque não possui conceito, mas é um símbolo da língua (portuguesa), porque faz parte dela. Logo, para ser palavra, é preciso ter um símbolo ou conjunto de símbolos (sons) que, ao se transformarem em signo, adquirem conceito, ou que se transformem em signo ao adquirirem conceito - há simultaneidade nesse processo pelas explicações de Humboldt.

Humboldt estudou a comunicação verbal pelo 
aspecto da manifestação em sons articulados. Para ele era na materialização que estava a excelência de uma língua, tanto do ponto de vista da nação como do indivíduo. Quanto mais bem determinados estiverem os sons articulados de um discurso mais exatos serão os conceitos vinculados. Como som articulado, o signo representa os elementos da linguagem, da língua e do pensamento, bem como do discurso. Existe na materialização em sons articulados - imagem acústica, além do estímulo material sensível e o conceito, a identidade da língua, como som inconfundível entre qualquer língua do mundo, e a identidade do falante, cujo som articulado em sua voz é inconfundível entre todos os falantes. A língua contribui com seus aspectos tipológicos e de cultura e o indivíduo com seu conhecimento da língua e na língua e seu aparelho fonador: a qualidade do discurso é resultado da intersecção desses fatos aprendidos.

Llamamos palabra al signo que corresponde a un concepto. La sílaba forma una unidad sonora; solo se convierte en palabra cuando obtiene una significatividad propia, lo que con frecuencia requiere la unión de varias sílabas. Por eso la palabra muestra una doble unidad, la del sonido y la del concepto. Es así como las palabras se convierten en los verdaderos elementos del habla, ya que las sílabas carentes de significación propia no pueden considerarse realmente como tales. Si imaginamos la lengua como un segundo mundo, objetivado por el individuo desde sí mismo a partir de las impresiones que recibe del mundo verdadero, las palabras serán los objetos individuales de ese mundo, y por ello les conviene La condición de individuos, que debe preservarse también en su forma (...) En la realidad no es el habla la que se compone de palabras que le preceden, sino que son, a la inversa, las palabras las que nacen del conjunto del discurso (...) La palabra es el límite hasta el cual la lengua ejerce espontáneamente su labor conformadora. La palabra simple es la flor perfecta brotada de ella. En la palabra el producto terminado pertenece a la lengua misma. En cambio a la frase y al discurso la lengua se limita a prescribir-les una forma reguladora (HUMBOLDT 1990: 98).

\section{Para Saussure: os signos da língua}

A língua está composta por signos linguísticos concretos de natureza essencialmente psíquica.
Saussure, no Curso de Linguística Geral (1995: 80), afirmou que "o signo linguístico une não uma coisa e uma palavra, mas um conceito e uma imagem acústica". Na língua só existem imagens acústicas feitas de unidades de sons articulados: os fonemas. Saussure demonstrou que não são os sons que foram articulados pelo falante, mas as impressões psíquicas.

O som é uma coisa concreta, como coisa concreta não pode chegar até o centro de processamento das informações no cérebro, assim, o que é transportado desde os ouvidos até o cérebro são as impressões psíquicas que os sons articulados causam nos indivíduos que recebem a mensagem. Então, a imagem acústica não é material e sim psíquica. A sensação de que ela é material deve-se à necessidade que os ouvintes têm de separá-la do conceito, que é claramente psíquico. Outra razão é o fato de a imagem acústica ter uma origem externa ao indivíduo, na forma de uma estrutura física, que é o som articulado. Por isso, parece inevitável concluir que o signo linguístico é sempre composto por dois elementos de natureza completamente psíquica: a imagem acústica e o conceito.

Pode-se afirmar que não há possibilidade de separação entre os dois elementos do signo linguístico. Saussure detectou um problema de terminologia relativo ao uso que era feito da palavra signo. Ele relembrou que o uso corrente dessa palavra era como designativo apenas da imagem acústica. Argumentou que, quando se usa um determinado segmento sonoro - um signo -, esse segmento exprime um conceito, que leva à conclusão de que a parte perceptível implica diretamente a ideia total, ou seja, a imagem acústica e o conceito. Por isso, propôs que o termo signo fosse empregado para designar a unidade completa: conceito mais imagem acústica. Ainda, propôs, para desfazer qualquer ambiguidade, que o termo conceito fosse substituído por significado e o composto imagem acústica, por significante.

O significado está ligado ao significante, logo, quando alguém emite um som articulado (significante, um som significante, ou melhor, aquilo que se 
encarrega de fazer um signo significar), esse som corresponde a uma convenção social relativa a uma ideia ou coisa (o significado, algo significado, ou melhor, aquilo que o signo está encarregado de significar). Esse significanteestimula na mente receptora o reconhecimento do significado (a ideia ou coisa referida pelo signo). $O$ processo de relacionamento entre as duas partes do signo é realizado por um vínculo estabelecido socialmente que faz com que todos os falantes reconheçam essa relação, como se existisse uma combinação espontânea entre todos. Em síntese, eles são forçados, pela própria vontade ou necessidade de constituição ou preservação do grupo, a aceitar os signos tal como eles se apresentam. O significante é relacionado no pensamento do falante ao significado por um vínculo completamente arbitrário: não há nenhuma relação de sugestão entre a estrutura sonora e o significado. Assim, qualquer unidade significante poderia ser relacionada a qualquer significado, em nada modificando 0 valor do significado e nem a relação dele com a cadeia sincrônica.

Saussure não discutiu a relação entre 0 significante e seu referente, ou a intenção originária que criou o significante. Entretanto, explicou outra questão que também implica na sugestão ou não do signo: a diferença entre o arbitrário absoluto e o arbitrário relativo. Mostrou a diferença que existe entre um termo que não é direcionado em hipótese alguma para o referente ou para o significado e um termo que traz em sua concepção acústica ou significante a ideia da coisa ou de sua significação. Usou como exemplo dessas circunstâncias os numerais. Assim, vinte, dez, nove etc. não têm, em sua estrutura, a ideia da quantidade a que fazem referência, ou seja, não apresentam sugestão alguma entre o significante e o significado. No entanto, em línguas como o francês e o português, os numerais como quatre-vingt "oitenta", quatre-vingt-dix-huit "noventa e oito", dezenove, dezoito, vinte e nove etc., de acordo com sua estrutura acústica, oferecem uma análise de seu significado. Esses signos, em relação ao vinte, dez, nove, que são completamente imotivados, são relativamente motivados. Também são relativamente motivados termos derivados que são variações num mesmo campo de significação: vaqueiro, fruteira, cerejeira, macieira etc. De todas as formas que podem ser analisadas e apontadas como formas com origem sugestiva, Saussure é categórico quanto ao fato de que, por mais que se encontre sugestão num termo, não existe sugestão absoluta, porque a relação entre os termos, quando separados, que formam o termo derivado, nunca é absolutamente igual no resultado derivado, principalmente por causa das mutilações que as arrumações fonéticas tendem a fazer.

O sistema da língua, explicou Saussure, repousa sobre o princípio irracional da arbitrariedade do signo. No entanto, as forças da racionalidade tendem para a amenização desse caos natural do sistema linguístico. Essa inteligência cria ordem e certa regularidade em muitas das partes da língua. Desse modo, boa parte dos signos é recuperável pelo raciocínio lógico assentado nos hábitos e fórmulas da língua. Como a maior parte do sistema linguístico traz em si a estrutura que recebeu da natureza, esse mecanismo de reconstrução do sistema pela racionalidade deve ser estudado como uma diminuição ou atenuação das estruturas absolutamente arbitrárias. Essa fórmula de organizar o caos linguístico visa, certamente, a facilitar a relação com a imensa quantidade de signos possíveis na língua. Muito importante para a linguística, quanto a mudanças nas línguas, é a afirmação: "a própria arbitrariedade do signo põe a língua ao abrigo de toda tentativa que vise a modificá-la" (SAUSSURE 1995: 87). As línguas não mudam em seu estado sistemático, como linguagem estruturada. A mudança está numa infidelidade relativa ao passado, acima de tudo o signo é continuidade, por isso tem condições de sofrer alterações: (SAUSSURE 1995: 89) "o signo está em condições de alterar-se porque se continua" (...) "a infidelidade ao passado é apenas relativa".

O signo é instalado no discurso como unidade concreta, material e forma física. Por isso, cada signo ocupa um espaço fixo e determinado. Na verdade, o significante toma espaço na construção discursiva por 
ter a característica de matéria, sendo realizado, desse modo, numa ordem que prevê o concurso do tempo. Esse é o espaço ocupado pelo significante: de acordo com o tempo empregado para realizá-lo. Isso equivale a dizer que dois significantes não ocupam o mesmo espaço/tempo, é necessário respeitar a forma física de cada um, porque eles sempre aparecem numa cadeia linear. A escrita, segundo Saussure, é particularmente constituída por essa característica do signo linguístico. Retoma-se a questão da mudança. De fato o afrouxamento da relação entre os elementos do signo acontece no uso ou na fala, portanto, no pensamento, quando os indivíduos fazem as palavras significar suas ideias particulares.

Saussure não deixou dúvida de que a relação entre significante e significado seja arbitrária, até mesmo nos casos das onomatopeias, nas quais fica difícil afastar toda e qualquer sugestão entre o significante e o objeto/referente. Tal concepção deriva da atitude metodológica de Saussure. Quando estabeleceu como objeto de estudo a língua, estrutura concreta, o signo apresentado foi aquele que compõe na memória a linguagem estruturada, em que uma forma representa um conhecimento. Tomado por esse aspecto, afastada qualquer interferência dos indivíduos e de seus atos de particularização das ideias, tudo é absolutamente estável, durável e constante. A sugestão implica num processo de analogia entre os elementos e isso somente é possível quando um pensamento agita as ideias e os signos. Isso somente ocorre nos exercícios de fala.

O signo linguístico une não uma coisa e uma palavra, mas um conceito e uma imagem acústica. Esta não é o som material, coisa puramente física, mas a impressão psíquica desse som, a representação que dele nos dá o testemunho de nossos sentidos; tal imagem é sensorial e, se chegamos a chamá-la "material", é somente neste sentido, e por oposição ao outro termo da associação, o conceito, geralmente mais abstrato (...) o signo linguístico é, pois, uma entidade psíquica de duas faces (...) esses dois elementos estão intimamente unidos e um reclama o outro (SAUSSURE 1995: 80) (...) o caráter arbitrário do signo nos fazia admitir a possibilidade teórica da mudança; aprofundando a questão, vemos que, de fato, a própria arbitrariedade do signo põe a língua ao abrigo de toda tentativa que vise a modificá-la (SAUSSURE 1995: 87) (...) o signo está em condições de alterar-se porque se continua. O que domina, em toda alteração, é a persistência da matéria velha; a infidelidade ao passado é apenas relativa. Eis porque o princípio de alteração se baseia no princípio de continuidade (SAUSSURE 1995: 89).

\section{Para Bakhtin: signo ideológico e semiótico}

Na obra Marxismo e filosofia da linguagem, Bakhtin (1995) propôs o signo como semiótico e como produto ideológico de uma realidade. Para ser semiótico, todo signo precisa de um corpo físico/ material e uma significação. A semiose ocorre exatamente no encontro entre essas duas partes do signo: a representação material e a significação. Importante dizer que, nessa obra, o ponto em debate é a linguagem, ou seja, da estrutura realizada pelo pensamento para significar. Desse modo, toda representação ideológica deriva de uma situação social organizada por indivíduos. A materialidade da linguagem, independentemente de qual realidade 0 signo estiver atrelado, sempre é natural ou social, mas sempre depende do indivíduo, ou seja, de seus sentidos e dos valores envolvidos.

Bakhtin disse (1995) que tudo que for ideologia tem um referente fora de si mesmo, então, têm-se sempre duas realidades: uma ideológica e uma material (social ou natural). Se tudo que é ideológico é signo, porque sem signos não existiria ideologia, e se todo signo é semiótico, porque remete às duas realidades, então, tudo que é ideológico é semiótico e possui uma realidade fora da ideologia. Logo, a representação em signos de uma coisa é sempre uma materialização em outra substância, ou infraestrutura de linguagem, de uma realidade física, social ou natural, em uma forma, ou superestrutura.

Existem dois mundos, um que se costuma chamar de real, em que se encontram os fenômenos da natureza, o material tecnológico e os artigos de consumo, e outro que Bakhtin chamou de mundo dos signos, que se torna particular, porque "todo signo está sujeito aos critérios de avaliação ideológica" (BAKHTIN 1995: 32). Esse universo de signos é também o universo da ideologia. O encontro entre as partes do signo coloca em jogo o ideológico e o valor 
semiótico. Tudo que é ideológico tem valor semiótico. Para ter valor semiótico, tudo precisa ser signo, logo, tudo que é signo tem valor semiótico.

O signo é pertencente ao mundo exterior como qualquer objeto, porque ele existe somente na interação entre os indivíduos. Desse modo, qualquer e todos os signos pertencem ao social, determinados pelo ideológico que é a matéria social dos signos. A questão importante a ser salientada é a de que, para que existam os signos, é preciso que haja sociedade, ou seja, que os indivíduos estejam socialmente organizados, portanto, os signos são elementos das instituições sociais. Daí poder aplicar com absoluta segurança aos signos linguísticos os caracteres de ideológicos e de semióticos por excelência, porque são pertencentes à língua. Eles são criados a partir de uma função ideológica, para representá-la, desse modo, sempre estarão determinados por ela. Signo e função ideológica jamais poderiam se separar.

A unidade mais conhecida da língua é a palavra, segundo Bakhtin, (1995: 36) "um fenômeno ideológico por excelência". Disse isso e, para completar e explicar, disse: "a palavra é o modo mais puro e sensível de relação social". Para trocar em miúdos, um pouco mais, as palavras existem como objetos nas relações de troca de informação e de comercialização entre os indivíduos. Deve-se considerar também 0 fato de elas serem as portadoras do conhecimento e nelas o pensamento dar forma ao conhecimento. Elas apresentam uma característica geral: são ideologicamente neutras. São ideologicamente específicas quando são atualizadas no discurso, podendo preencher qualquer função ideológica. Isso significa que dependem do uso do falante para se atualizarem como unidade da língua e da ideologia.

O ser humano pode se comunicar por muitas formas de linguagem. A ideologia pode ser transmitida, desde a enunciação, por qualquer um dos sentidos, fazendo uso da substância que possa ser uma forma reconhecível psiquicamente. Porém, a comunicação na vida cotidiana privilegia o uso da palavra, por esse prisma pode-se dizer que Bakhtin reconheceu a primazia da língua como veículo de comunicação e os sons articulados como o meio mais utilizado. Uma palavra está na dependência da articulação, por isso representa um signo interior, porque expressa não somente um significado social previamente estabelecido, mas também idiossincrasias típicas dos falantes e do momento em que estiver sendo produzida, ou seja, representa estados emotivos, como paixões, vontades, raciocínios e ideologias.

Concretamente, as palavras representam signos ideológicos estabelecidos socialmente e subsistem enquanto estiverem em uso, ou seja, qualquer criação ideológica deve ser revitalizada pelo discurso. O discurso produz uma imanência, a partir de uma estrutura de ideologias previamente produzidas apoiada nas palavras, que são os verdadeiros signos das ideologias. Desse modo, o discurso revitaliza constantemente as palavras como signo de uma ideologia, se acontecer de parar esse processo, o signo desaparece. Isso não quer dizer que a palavra desapareceu, ela pode continuar existindo como signo de outras ideologias. Assim sendo, toda a estrutura ideológica em uso, de estudo ou de análise da linguagem, está fundamentada numa filosofia do signo ideológico. Esse pressupõe uma manifestação do pensamento nos objetos sociais, as palavras, e na estrutura de linguagem específica para comunicação verbal, a língua.

Toda a relação entre infraestrutura e superestrutura, segundo Bakhtin, é de causalidade. Todo processo de transformação ideológica percorre o caminho que vai da materialidade do discurso, som articulado na linguagem verbal, até o conjunto da estrutura indivisível. As mudanças partem sempre do arranjo material e faz remissão ao conceito. Desse modo, considerando o processo inteiro, é na superfície do discurso onde as formas de ideologia variam. É a materialidade substanciada da forma do discurso que faz o sentido ser significado e faz também variar os valores e as ideologias.

Há uma separação entre sentido e transformação ideológica. É claro que isso ocorre no interior de um contexto. Qualquer transformação no espaço físico temporal e espacial de interferência da 
ideologia resulta num novo sentido, como duas partes que se encaixam com perfeição. Toda mudança parte da instalação do pensamento de um indivíduo nesse espaço físico. Isso significa que a reação que ocorreria na estrutura da linguagem ou ideologia provém do pensamento dos indivíduos, são eles que são atingidos pelas mudanças, tanto como reflexo como refração do signo ideológico. Bakhtin, conforme exposto acima, chama esses dois elementos da formação da comunicação, em específico da comunicação linguística, de conjunto único e indivisível, ou de toda esfera ideológica, ou de superestrutura e de infraestrutura.

No signo linguístico essa relação é claramente explicita porque a comunicação verbal é intensa e muito frequente por isso assimila todos e mínimos ajustes que ocorram na infraestrutura. Pode-se avançar na questão linguística e fazer lembrar que o sistema verbal em sons articulados produz signos que substituem qualquer realidade no pensamento. Assim, toda forma de pensamento se realiza primeiro na infraestrutura do signo ideológico, depois em sons articulados dentro da superestrutura da língua. Sendo então o espaço privilegiado da comunicação entre os seres humanos, o material verbal do discurso linguístico apresenta as mínimas alterações que o pensamento possa ter alcançado, mantendo uma refração perfeita entre a esfera ideológica, língua e cultura e entre a infraestrutura, sons articulados e pensamento.

Bakhtin nomeou a realidade refletida e refratada pelo signo como psicologia social, como fez Saussure, e como espírito do povo, como fizera Humboldt. Saussure, no entanto, não discutiu o processo de materialização na fala. Humboldt no início do século XIX o fizera. Para ele, o discurso é sempre nacionalmente individual, ou seja, manifesta o espírito do povo e a idiossincrasia. Bakhtin disse que na enunciação a psicologia social se manifesta inteiramente na palavra, no gesto e no ato. No enunciado, o indivíduo materializa tudo o que de ideológico contém e mantém dentro de si. Sendo ele uma enunciação, inevitavelmente o princípio é de uma continuidade entre a coletividade e a individualidade. Essas são elementos do pensamento que não se separam no interior de nenhuma estrutura de linguagem e são processos prototipicamente realizados no discurso linguístico.

Bakhtin estudou a comunicação pelo viés da manifestação do pensamento, portanto, da linguagem, o órgão do cérebro responsável pelas estruturações. Considerou a língua como o principal mecanismo da comunicação em sociedade, sendo a palavra o lugar privilegiado da manifestação das ideologias. Separou em infraestrutura e superestrutura os elementos que compõem o signo: da primeira faz parte tudo o que é exterior ao pensamento e da segunda tudo o que é interior, e descartou a possibilidade de divisão mesmo que metodológica entre essas partes. É desse ponto de vista, da linguagem estruturada numa materialidade, sons articulados na linguagem verbal, que definiu o signo como uma atualização num material de infraestrutura da ideologia significada na forma de uma superestrutura.

Os signos também são objetos naturais, específicos, e, como vimos, todo produto natural, tecnológico ou de consumo pode tornar se signo e adquirir, assim, um sentido que ultrapasse suas próprias particularidades. Um signo não existe apenas como parte de uma realidade; ele também reflete e refrata uma outra. Ele pode distorcer essa realidade, ser-lhe fiel, ou apreendê-la de um ponto de vista específico, etc. Todo signo está sujeito aos critérios de avaliação ideológica (isto é: se é verdadeiro, falso, correto, justificado, bom, etc.) . O domínio do ideológico coincide com o domínio dos signos: são mutuamente correspondentes. Ali onde o signo se encontra, encontra-se também o ideológico. Tudo que é ideológico possui um valor semiótico (BAKHTIN 1995: 32) (...) esse espaço semiótico e esse papel contínuo da comunicação social como fator condicionante não aparecem em nenhum lugar de maneira mais clara e completa do que na linguagem. A palavra é o fenômeno ideológico por excelência. A realidade toda da palavra é absorvida por sua função de signo. A palavra não comporta nada que não esteja ligado a essa função, nada que não tenha sido gerado por ela. A palavra é o modo mais puro e sensível de relação social (BAKHTIN 1995: 36).

\section{Conclusão}

A questão historiográfica neste artigo é a da 
continuidade conceitual: existe obviamente uma profunda ligação entre os três estudiosos. Foi justamente a discussão que Bakhtin fez sobre os conceitos de Humboldt e de Saussure que despertou o interesse em dispor os três num mesmo lugar. No entanto, o texto lida com a individualidade metodológica dos três, por isso evitou-se a comparação, optou-se pela síntese de cada um em justaposição, permitindo uma leitura cronológica e comparativa do tema. Para propor a conclusão, é preciso lembrar que Humboldt foi um Gramático Comparatista, do período platônico-antropocêntrico e da afirmação do racionalismo. Saussure foi um filólogo da neogramática e do cientificismo. E Bakhtin viveu numa nação subjugada por uma filosofia opressora e muito violenta, em que os mecanismos de coerção ideológica estavam muito evidentes e operavam no sentido de igualar todos os indivíduos.

Humboldt entendeu a linguagem pelo elemento da materialidade e da individualidade: 0 som articulado. Para ele, a beleza dos elementos da língua, a identidade nacional, o espírito da língua, a perfeição do discurso etc. estavam na abundância e precisão dos sons articulados, inclusive e principalmente na competência da língua nacional e da língua do falante para transmitir seus pensamentos. Para Humboldt, fora do elemento material e racional não existiria manifestação, numa evidente asseveração dos conceitos racionalistas kantianos para a metafísica e o inatismo, nem perfeição, logo, o grotesco e o sublime eram estágios perfeitos de aperfeiçoamento.

Saussure tomou a língua, a estrutura básica para as relações sociais, como ponto de partida para suas pesquisas e conclusões. Definiu didaticamente os três elementos que comporiam o exercício do pensamento e da inteligência: linguagem, língua e fala. A linguagem como abstrata e inata, também no sentido kantiano, seria inata porque é física. A fala como a materialização do pensamento, tendo como formas, para o revestimento plástico, os fonemas, que são unidades compostas na articulação de sons. A língua, a forma para o pensamento, se torna a fórmula (estrutura de linguagem) para realizar todas as coisas.

Bakhtin estudou como a estrutura se torna significação e como o pensamento se torna estrutura. O sentimento (ou sensação) existe na sociedade para todos os indivíduos, mas, para a explicitação da sensação numa forma estruturada, é preciso que um deles consiga completar todos os elementos dessa sensação no pensamento e então possa realizar a estrutura da linguagem: somente assim ele poderá dar nome a essa sensação e explicar sua composição. Uma vez estruturada na superestrutura e nomeada, outros indivíduos poderão completar no pensamento as sensações e adaptá-las à realidade e à ideologia de seus discursos.

O signo, para os três pensadores, tem sua definição adaptada ao método de cada um, por isso o evidente mecanismo de ruptura de cada conceito. $O$ signo para Humboldt é marcado por pura identidade: os sons articulados são identificados na língua. Mesmo que eles pudessem ser vinculados à articulação de sons muito semelhantes em outras línguas, jamais um falante nativo de uma língua será capaz de se disfarçar em falante nativo de outra língua. Os conceitos expressos por esses sons articulados também estão vinculados à cultura, de tal forma que nunca poderiam ser plenamente expressos nos sons articulados de outras línguas. Racionalmente, todos os elementos da natureza e da língua nacional, como a tradutora principal da natureza, são únicos (individuais) e não poderiam nunca ser repetidos.

Para Saussure, o signo é uma representação social. Ele não estudou, sem negar a existência, os elementos da fala e se restringiu ao contexto da sociedade para explicar a comunicação entre os seres humanos. Assim, o signo passa a ser algo fora do controle do indivíduo, pertencendo à coletividade. Do ponto de vista da coletividade, a relação entre significante e significado é puramente arbitrária, a única análise possível é da convenção social entre uma articulação de sons e um conceito, ambos préestabelecidos socialmente. A língua é a estrutura que se coloca entre os indivíduos e os signos, seus objetos, e que também se coloca entre os indivíduos 
e que jamais pertenceria somente a um deles.

Bakhtin leu Humboldt e Saussure e propôs o signo como a realização do encontro entre 0 pensamento e a articulação. Oprimido pelas estruturas sociais e manifestando-se por essas estruturas sociais, principalmente a língua, o indivíduo faz das ideologias sociais suas ideologias e aplica seus pensamentos (ideologias) aos sons articulados. Nesse momento ocorre a semiose, logo, todo signo é semiótico. Inevitavelmente, todo signo é pleno dos elementos ideológicos das estruturas e pleno dos arranjos da identidade ideológica do indivíduo que atualiza a estrutura pelo discurso. É pela estrutura da linguagem que o signo pode existir como semiose e é dessa perspectiva que Bakhtin o propôs.

É inevitável perceber que a visão de Bakhtin, como leitor dos outros dois, se aproxima mais da de Humboldt do que da de Saussure. Afastando questões de contexto, a linguagem é intimamente relacionada ao pensamento, lugar em que todos os seres inteligentes são absolutamente individuais. A perspectiva do som articulado e da linguagem prima pela marca da individualidade, ou seja, é preciso ver o que tem de diferente cada um de seus elementos, na estruturação e na manifestação, para saber o que cada um é. Ao contrário, a língua se coloca em meio àquilo que todos e cada um dos elementos de uma coletividade têm em comum, obrigando a agrupar as diferenças, nessa perspectiva, como afirmou Saussure, a língua é um princípio de classificação.

\section{Referências}

ARISTÓTELES. Arte retórica e poética. Rio de Janeiro, Ediouro, coleção Universidade.

ARISTÓTELES. Organon: Catégories e de I'interprétation. Paris, J. Vrin, 1946.

ARNAULD e LANCELOT. Gramática de Port-Royal. São Paulo, Martins Fontes, 2001.

BAKHTIN, Mikhail. Marxismo e filosofia da linguagem. São Paulo, Hucitec, 1995.

BENVENISTE, Émile. Problemas de lingüística Geral I e II. Campinas-SP, Pontes, 1995. Trad. de Maria da Glória Novak e Maria Luisa Neri.
CONDILLAC. É. Bonnot de. Traité des sensations. Paris, Fayard, 1754.

COSERIU, Eugenio. O homem e sua linguagem. Rio de Janeiro/ São Paulo, Presença/EDUSP, 1982. Trad. de Carlos Alberto da Fonseca e Mário Ferreira.

COSERIU, Eugenio. Tradição e novidade na ciência da linguagem. Rio de Janeiro/São Paulo, Presença/EDUSP, 1982. Trad. de Carlos Alberto da Fonseca e Mário Ferreira.

FALCÃO, Francisco. Iluminismo. São Paulo, Ática, 1994. Série Princípios.

GREIMAS, A. J. e COUTÉS, J. Dicionário de semiótica. São Paulo, Cultrix, 1979.

HJELMSLEV, Louis. Essaislinguistiques. Paris, Minuit, 1968.

HJELMSLEV, Louis. Prolegômenos a uma teoria da linguagem. Paris, Minuit, 1945.

HUMBOLDT, Wilhelm Karl von. Sobre ladiversidad de la estrutura dellenguaje humano y su influencia sobre eldesarrollo espiritual de lahumanidad. Barcelona, Anthropos, 1990.

HUMBOLDT, Wilhelm Karl von. Sobre elorigen de las formas gramaticales $y$ sobre su influencia eneldesarrollo de lasideas - Carta a M. Abel Rémusat sobre lanaturaleza de las formas gramaticalesen general $y$ sobre elgenio de lalengua china en particular. Barcelona, Anagrama, 1972.

KANT, Immanuel. Critique de laraizonpure. Paris, Flammarion, 1976.

LOCKE, John. Ensaio acerca do entendimento. São Paulo, Abril cultural. Coleção os Pensadores.

Neves, Maria Helena de Moura. A Gramática. São Paulo, UNESP, 2002.

PLATÃO. Diálogos: Sócrates e Crátilo. Coleção Os pensadores.

SAUSSURE, Ferdinand de. Curso de linguística geral. São Paulo, Cultrix, 1995. Trad. de Antônio Chelini, José Paulo Paes e IzidoroBlikstein. 